\title{
Factors associated with transmission of severe acute respiratory syndrome among health-care workers in Singapore
}

\author{
M. D. TELEMAN ${ }^{1 *}$, I. C. BOUDVILLE ${ }^{2}$, B. H. HENG ${ }^{3}$, D. ZHU ${ }^{3}$ AND Y. S. LEO \\ ${ }^{1}$ Department of Clinical Epidemiology, Tan Tock Seng Hospital, Singapore \\ ${ }^{2}$ GlaxoSmithKline Biologicals, Singapore \\ ${ }^{3}$ Disease Management, National Healthcare Group, Singapore \\ ${ }^{4}$ Communicable Disease Centre, Tan Tock Seng Hospital, Singapore
}

(Accepted 9 June 2004)

\section{SUMMARY}

Between 1 and 22 March 2003, a nosocomial outbreak of Severe Acute Respiratory Syndrome (SARS) occurred at the Communicable Disease Centre in Tan Tock Seng Hospital, Singapore, the national treatment and isolation facility for patients with SARS. A case-control study with 36 cases and 50 controls was conducted of factors associated with the transmission of SARS within the hospital. In univariate analysis, contact with respiratory secretions elevated the odds ratio to 6.9 (95\% CI 1·4-34.6, $P=0 \cdot 02$ ). Protection was conferred by hand washing (OR 0.06, $95 \% \mathrm{CI}$ $0 \cdot 007-0 \cdot 5, P=0.03$ ) and wearing of N95 masks (OR $0 \cdot 1,95 \%$ CI $0 \cdot 03-0 \cdot 4, P=0.001$ ). Use of gloves and gowns had no effect. Multivariate analysis confirmed the strong role of contact with respiratory secretions (adjusted OR 21·8, 95\% CI 1·7-274·8, $P=0 \cdot 017$ ). Both hand washing (adjusted OR 0.07, 95\% CI 0.008-0.66, $P=0 \cdot 02$ ) and wearing of N95 masks (adjusted OR $0 \cdot 1$, $95 \%$ CI $0 \cdot 02-0 \cdot 86, P=0 \cdot 04)$ remained strongly protective but gowns and gloves had no effect.

\section{INTRODUCTION}

Singapore was one of the countries most affected in the first outbreak of severe acute respiratory infection (SARS), with a total of 238 cases occurring between 1 March and 5 May 2003 [1], out of a global total of 8098 probable cases that occurred worldwide between 1 November 2002 and 31 July 2003 [1].

The epidemiological and microbiological evidence thus far indicates that the aetiological agent, now designated the SARS coronavirus (SARS-CoV) [2-4], spreads predominantly from person-to-person. Infection mainly occurs either via the projection of virusbearing respiratory droplets onto mucous membranes of the eyes, nose and mouth across a short (arbitrarily

\footnotetext{
* Author for correspondence: Dr M. D. Teleman, Department of Clinical Epidemiology, Tan Tock Seng Hospital, 142 Moulmein Road, Singapore 308087.

(Email: monica_teleman@ttsh.com.sg)
}

defined as $1 \mathrm{~m}$ ) distance, i.e. droplet transmission [5, 6], or via direct or indirect (involving fomites) contact with an infected source patient, i.e. contact transmission [6]. Contact transmission is especially likely among health-care workers (HCWs). Spread by fomites depends on the survivability of the virus in the environment, which for SARS has been demonstrated to be as long as a few days [7]. An unusual route of transmission was implicated by epidemiological investigation of an outbreak in a Hong Kong apartment block, in which it was hypothesized that exhaust fans causing backflow of air through a faulty sewage system may have been responsible for the widespread circulation of virus-bearing faecal droplets throughout the building [8]. The subsequently reported clinical presentation of these cases, however, supports possible faecal-oral transmission as an alternative hypothesis [4].

Apart from 'superspreaders', for which phenomenon the specific host and/or environmental factors 
responsible remain to be elucidated [7], the infectiousness of SARS is in general less than that of most other respiratory infections. Despite numerous unprotected exposures, no transmission occurred among HCWs in the United States [9]. Estimates of the basic reproduction ratio $R_{0}$, average around 3 [7], compared to estimates of $11-18$ for measles $[10,11]$ and up to 30 for influenza $[12,13]$. Case-fatality ratios ranged from $0 \%$ to over $50 \%$, with the overall case fatality estimated at approximately $15 \%$ [7]. In Singapore, the case-fatality ratio was $13 \cdot 6 \%$ [14].

A hallmark of the SARS outbreak in affected countries was the amplification of transmission that occurred within health-care settings [7]. The occurrence of hospital and nursing-home clusters involving staff and patients caused much alarm. Initial perceptions of infectiousness were coloured by the apparent efficiency and unpredictability of nosocomial transmission of SARS [7, 15]. Several high-profile fatalities among HCWs both locally and internationally [16, 17] also led to unduly grim perceptions of its virulence. Scientific studies were urgently undertaken to ascertain the risk level associated with various therapeutic settings and procedures and inform recommendations on the use of personal protective equipment (PPE) by HCWs [18].

This report presents results of a case-control study of the risk and protective factors for nosocomial transmission of SARS in Tan Tock Seng Hospital (TTSH), Singapore in an outbreak which affected a total of 44 HCWs.

\section{Chronology of events}

On 6 March 2003, the Ministry of Health, Singapore was notified of a cluster of atypical pneumonia in three patients with a preceding history of travel to Hong Kong [8]. The health authorities having been alerted by the World Health Organization (WHO), these and subsequent patients were isolated at a central location, the Communicable Disease Centre (CDC) at TTSH. On 22 March, TTSH, Singapore's second largest general hospital, was designated as the central referral, screening and treatment centre for SARS. The CDC is a specialist facility with a national role, staffed by experts in clinical infectious diseases, hospital infection control and public health.

The nosocomial outbreak in TTSH began shortly after the admission on 1 March of the first index patient (case 1), a 23-year-old female who had returned from a visit to Hong Kong. She was managed initially as

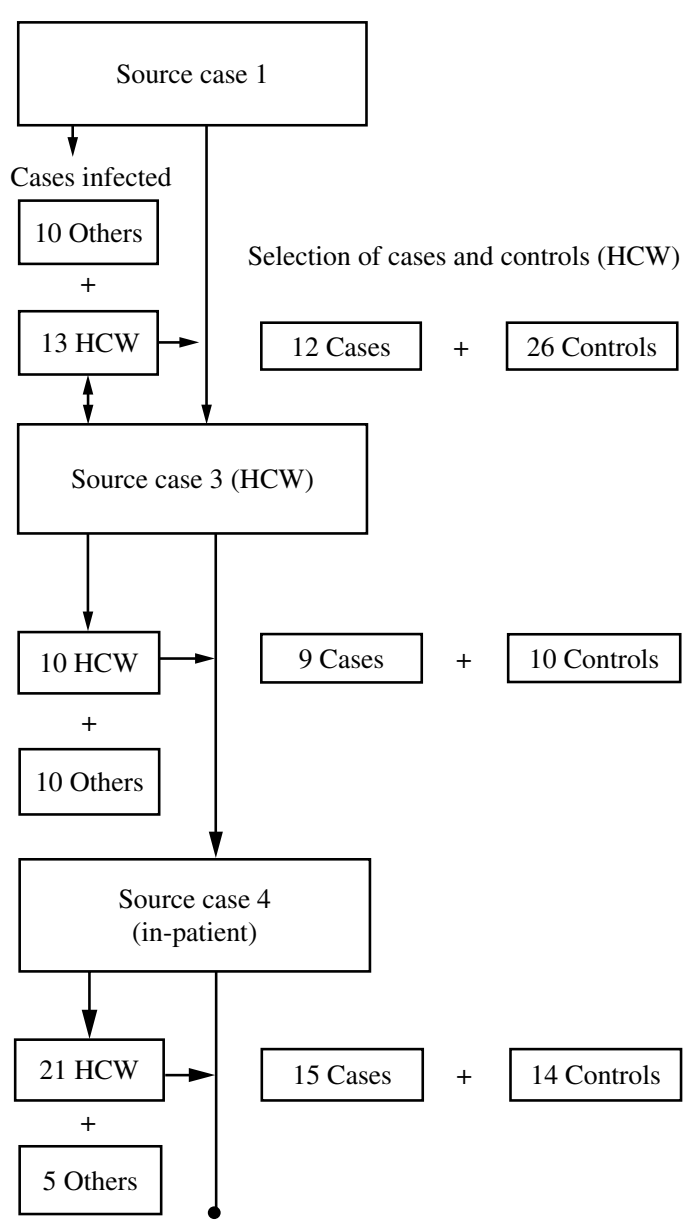

Fig. Source cases for SARS transmission among health-care workers (HCW) and selection of cases and controls in the study.

for straightforward community-acquired pneumonia. After 5 days, a deterioration in her condition, which coincided with recognition of a second index case (case 2), raised suspicions that led to her being isolated 5 days after admission. Shortly after, clusters of cases emerged in three separate wards, all traceable to case 1 . She had already infected 23 cases, including 13 $\mathrm{HCWs}$, before she was isolated. No secondary cases arose from case 2. Case 3, a secondary case to case 1, was admitted to another ward where she infected a total of 20 persons, including $10 \mathrm{HCWs}$ before she was isolated 3 days later. An in-patient (case 4) who shared a cubicle with case 3 was subsequently transferred to a coronary care unit when her clinical condition deteriorated. Before her isolation 8 days later, she had infected a total of 26 persons, including 21 HCWs. Over 21 days, secondary and tertiary transmission occurred within the hospital from source cases 1, 3 and 4, involving a total of $44 \mathrm{HCWs}$ and 25 patients (Fig.). 


\section{Enhanced personal protective measures}

By the end of the first week of March, HCWs were employing N95 masks for personal protection when nursing case 1 and her contacts. These are health-care particulate respirators with at least $95 \%$ filtration efficiency against non-oily, solid and liquid aerosols [17]. By the end of week 2 PPE against contact, droplet and respiratory transmission had been adopted by HCWs attending patients in areas involved in SARS screening or treatment (intensive care unit, emergency department and communicable disease wards). By 22 March 2003, N95 masks were required when treating any patient in the hospital. Beginning 6 April 2003, the wearing of gloves, gowns and N95 masks was enforced for contact with all patients in the hospital, with visors additionally advised for procedures with a risk of splashing. On 25 April 2003, goggles were made mandatory for all patient contact. Later, a requirement of positive air purifying respirators (PAPR) for high-risk or aerosol-generating procedures was also imposed. Beyond 22 March 2003, no further intra-hospital transmission occurred.

\section{MATERIALS AND METHODS}

\section{Subjects}

HCWs with probable SARS admitted between 1 and 31 March 2003 were recruited as cases. Diagnosis was based on WHO's criteria of documented fever (temperature $>38^{\circ} \mathrm{C}$ ), presence of cough, shortness of breath or breathing difficulty, and a significant history of exposure to a SARS patient not more than 10 days prior to onset of symptoms, plus radiographic evidence of infiltrates consistent with pneumonia or respiratory distress syndrome (RDS) on chest X-ray (CXR) [20]. HCWs in whom an alternative diagnosis was eventually established were excluded from the list of probable SARS cases and also from the study. All cases included were subsequently confirmed by a positive serology result performed at the national referral laboratory.

We initially selected as controls all HCWs from SARS-affected wards who reported exposure to patients with probable SARS during the same period but who remained well. To establish exposure, respondents were asked if they had cared for any person on the list of probable SARS patients. Exposure was deemed to be definite where there was a history of being within close physical proximity $(1 \mathrm{~m})$ of a patient subsequently confirmed with SARS. For all patients not subsequently confirmed by serology, controls were excluded from final analysis.

\section{Epidemiological investigation and data collection}

Telephone interviews with cases and controls were carried out using a closed questionnaire by staff experienced in epidemiological investigations from the Department of Clinical Epidemiology of TTSH.

Information collected included demographic data (age, gender and ethnic group), occupation, history of medical conditions and vaccinations within the previous 5 years and history of performing procedures with transmission risk (date, place, type, duration and frequency). Incubation periods were estimated by ascertaining from subjects the date of onset of their first symptom and dates of first and last exposure. In cases with exposure to more than one SARS case, the source of infection was assigned based on the most likely range of incubation of 2-10 days. Subjects were questioned on their compliance with recommendations for personal protection, i.e. wearing of N95 masks, gloves, gown and consistent hand washing after patient contact.

\section{Statistical analysis}

For statistical analyses, differences in proportions observed between cases and controls were compared using $\chi^{2}$ or Fisher's exact test. Probability $(P)$ values of less than 0.05 were considered significant. Factors found to be significant in univariate analysis were included in forward logistic regression analysis. Potentially confounding covariates were selected among those where $P$ values were $<0 \cdot 2$ in the univariate analysis. Statistical analyses were performed using SPSS version 11.5 (SPSS Inc., Chicago, IL, USA) software.

\section{RESULTS}

\section{Descriptive epidemiology}

Of the 44 cases generated by source cases 1, 3 and 4 during the period under study, $36(82 \%)$ were successfully recruited, six were too ill to be interviewed and two died before they could be interviewed. A total of $50 \mathrm{HCWs}$ working in the same wards as the cases, with history of exposure but who did not develop disease, were included in the control group.

The demographic and epidemiological characteristics showed that the two groups were comparable 
Table 1. Univariate analysis of demographic and epidemiological characteristics

\begin{tabular}{|c|c|c|c|c|c|c|}
\hline & \multicolumn{2}{|c|}{ Cases $(n=36)$} & \multicolumn{2}{|c|}{ Controls $(n=50)$} & \multirow{2}{*}{$\begin{array}{l}\text { Crude OR } \\
(95 \% \text { CI })\end{array}$} & \multirow[b]{2}{*}{$P$ value* } \\
\hline & $n$ & $(\%)$ & $n$ & $(\%)$ & & \\
\hline \multicolumn{7}{|l|}{ Gender } \\
\hline Female & 32 & $(88 \cdot 9)$ & 49 & $(98 \cdot 0)$ & $6 \cdot 1(0 \cdot 7-57 \cdot 3)$ & $0 \cdot 16$ \\
\hline Male & 4 & $(11 \cdot 1)$ & 1 & $(2 \cdot 0)$ & & \\
\hline \multicolumn{7}{|l|}{ Ethnic group } \\
\hline Chinese & 20 & $(55 \cdot 6)$ & 17 & $(34 \cdot 0)$ & $2 \cdot 4(1 \cdot 0-5 \cdot 9)$ & $0 \cdot 04$ \\
\hline Non-Chinese & 16 & $(44 \cdot 4)$ & 33 & $(66 \cdot 0)$ & & \\
\hline \multicolumn{7}{|l|}{ Age group (years) } \\
\hline$<30$ & 23 & $(63 \cdot 9)$ & 28 & $(56 \cdot 0)$ & $1 \cdot 4(0 \cdot 3-1 \cdot 7)$ & $0 \cdot 5$ \\
\hline $30+$ & 13 & $(36 \cdot 1)$ & 22 & $(44 \cdot 0)$ & & \\
\hline Presence of comorbid condition & 6 & $(16 \cdot 7)$ & 9 & $(18 \cdot 0)$ & $0 \cdot 9(0 \cdot 3-3 \cdot 2)$ & $0 \cdot 9$ \\
\hline $\begin{array}{l}\text { History of vaccination in previous } \\
5 \text { years }\end{array}$ & 19 & $(52 \cdot 8)$ & 26 & $(54 \cdot 0)$ & $1 \cdot 03(0 \cdot 4-2 \cdot 7)$ & $0 \cdot 9$ \\
\hline \multicolumn{7}{|l|}{ Category of health-care worker } \\
\hline Doctors and nurses & 26 & $(72 \cdot 2)$ & 39 & $(78 \cdot 0)$ & $0 \cdot 7(0 \cdot 3-1 \cdot 9)$ & $0 \cdot 5$ \\
\hline Other health-care workers & 10 & $(27 \cdot 8)$ & 11 & $(22 \cdot 0)$ & & \\
\hline
\end{tabular}

* Using $\chi^{2}$ or Fisher's exact test.

Table 2. Univariate analysis of factors associated with transmission of SARS to health-care workers

\begin{tabular}{|c|c|c|c|c|c|c|}
\hline & \multicolumn{2}{|c|}{ Cases $(n=36)$} & \multicolumn{2}{|c|}{ Controls $(n=50)$} & \multirow{2}{*}{$\begin{array}{l}\text { Crude OR } \\
(95 \% \text { CI })\end{array}$} & \multirow[b]{2}{*}{$P$ value* } \\
\hline & $n$ & $(\%)$ & $n$ & $(\%)$ & & \\
\hline \multicolumn{7}{|l|}{ Distance to source of infection } \\
\hline$<1 \mathrm{~m}$ & 32 & $(88 \cdot 9)$ & 45 & $(90 \cdot 0)$ & $0 \cdot 9(0 \cdot 2-3 \cdot 6)$ & $0 \cdot 9$ \\
\hline \multicolumn{7}{|l|}{ Duration of exposure (min) } \\
\hline $60+$ & 21 & $(58 \cdot 3)$ & 24 & $(48 \cdot 0)$ & $0 \cdot 7(0 \cdot 3-1 \cdot 6)$ & $0 \cdot 4$ \\
\hline Wearing of N95 mask & 3 & $(8 \cdot 3)$ & 23 & $(46 \cdot 0)$ & $0 \cdot 1(0 \cdot 03-0 \cdot 4)$ & $0 \cdot 001$ \\
\hline Wearing of gloves & 10 & $(27 \cdot 8)$ & 22 & $(44 \cdot 0)$ & $0 \cdot 5(0 \cdot 2-1 \cdot 2)$ & $0 \cdot 1$ \\
\hline Wearing of gown & 5 & $(13 \cdot 9)$ & 13 & $(26 \cdot 0)$ & $0 \cdot 5(0 \cdot 1-1 \cdot 4)$ & $0 \cdot 2$ \\
\hline Touched patients & 29 & $(80 \cdot 6)$ & 40 & $(80 \cdot 0)$ & $1 \cdot 0(0 \cdot 4-3 \cdot 0)$ & $0 \cdot 9$ \\
\hline $\begin{array}{l}\text { Touched patients' personal } \\
\text { belongings }\end{array}$ & 28 & $(77 \cdot 8)$ & 43 & $(86 \cdot 0)$ & $0 \cdot 6(0 \cdot 2-1 \cdot 7)$ & $0 \cdot 3$ \\
\hline Contact with respiratory secretions & 8 & $(22 \cdot 2)$ & 2 & $(4 \cdot 0)$ & $6 \cdot 9(1 \cdot 4-34 \cdot 6)$ & $0 \cdot 02$ \\
\hline Performed venepuncture & 30 & $(83 \cdot 3)$ & 40 & $(80 \cdot 0)$ & $0 \cdot 8(0 \cdot 3-2 \cdot 4)$ & $0 \cdot 7$ \\
\hline Performed/assisted in intubation & 2 & $(5 \cdot 6)$ & 4 & $(8 \cdot 0)$ & $1 \cdot 5(0 \cdot 4-5 \cdot 4)$ & $0 \cdot 6$ \\
\hline Performed suction of body fluids & 8 & $(22 \cdot 2)$ & 11 & $(22 \cdot 2)$ & $1 \cdot 01(0 \cdot 4-2 \cdot 8)$ & 1 \\
\hline Administered oxygen & 7 & $(19 \cdot 4)$ & 10 & $(20 \cdot 0)$ & $1 \cdot 0(0 \cdot 3-2 \cdot 8)$ & 1 \\
\hline Hand washing after each patient & 27 & $(75 \cdot 0)$ & 46 & $(92 \cdot 0)$ & $0.06(0 \cdot 007-0 \cdot 5)$ & $0 \cdot 03$ \\
\hline
\end{tabular}

* Using $\chi^{2}$ or Fisher's exact test.

except for a higher proportion of Chinese than nonChinese in cases (Table 1).

\section{Univariate analysis}

Compared to the control population, a small and marginally significant elevation of the crude odds ratio (OR) for SARS was found for Chinese compared with
non-Chinese (OR 2.4, 95\% CI 1·0-5.9, $P=0 \cdot 048$ ) (Table 1). Contact with respiratory secretions substantially and significantly increased the odds of SARS (OR 6.9, 95\% CI 1·4-34.6, $P=0 \cdot 02$ ) (Table 2). A very large reduction in odds was achieved by consistent hand washing after patient contact (OR 0.06, $95 \%$ CI $0 \cdot 007-0 \cdot 5, P=0 \cdot 03)$. A large and highly significant reduction in odds was also achieved by the 
Table 3. Multivariate analysis of factors associated with transmission of SARS to health-care workers

\begin{tabular}{|c|c|c|c|}
\hline Covariate & Adj. OR* & $95 \% \mathrm{CI}$ & $P$ value \\
\hline \multicolumn{4}{|l|}{ Gender } \\
\hline Male & $2 \cdot 9$ & $0 \cdot 2-34 \cdot 0$ & $0 \cdot 4$ \\
\hline \multicolumn{4}{|l|}{ Ethnic group } \\
\hline $\begin{array}{l}\text { Chinese } \\
\text { Non-Chinese } \dagger\end{array}$ & $2 \cdot 0$ & $0 \cdot 7-6 \cdot 1$ & $0 \cdot 2$ \\
\hline Wearing of N95 mask & $0 \cdot 1$ & $0 \cdot 02-0 \cdot 9$ & $0 \cdot 04$ \\
\hline Wearing of gloves & $1 \cdot 5$ & $0 \cdot 3-7 \cdot 2$ & $0 \cdot 6$ \\
\hline Wearing of gowns & $0 \cdot 5$ & $0 \cdot 4-6 \cdot 9$ & $0 \cdot 6$ \\
\hline $\begin{array}{l}\text { Hand washing after } \\
\text { each patient }\end{array}$ & $0 \cdot 07$ & $0 \cdot 008-0 \cdot 7$ & $0 \cdot 02$ \\
\hline $\begin{array}{l}\text { Contact with } \\
\text { respiratory secretions }\end{array}$ & $21 \cdot 8$ & $1 \cdot 7-274 \cdot 8$ & $0 \cdot 017$ \\
\hline
\end{tabular}

* Adjusted odds ratio by forward-enter logistic regression.

$\dagger$ Reference category.

wearing of N95 masks when attending to patients (OR $0 \cdot 1,95 \%$ CI $0 \cdot 03-0 \cdot 4, P=0 \cdot 001$ ) (Table 2). Wearing of latex gloves (OR $0 \cdot 5,95 \%$ CI $0 \cdot 2-1 \cdot 2$, $P=0 \cdot 1$ ) and gowns (OR $0 \cdot 5,95 \% \mathrm{CI} 0 \cdot 1-1 \cdot 4, P=0 \cdot 2$ ) each halved the odds of infection, although both failed to achieve statistical significance.

\section{Logistic regression analysis}

The best fit was obtained by forward-entering the following covariates into the regression model: gender, ethnic group, wearing of N95 masks, wearing of gloves, wearing of gowns, hand washing after each patient contact, and contact with patients' respiratory secretions. The results (Table 3) show that contact with patients' respiratory secretions was independently and significantly associated with a greatly increased odds of infection (adjusted OR 21.8, 95\% CI 1.7$274.8, P=0.017)$. Conversely, hand washing after patient contact was strongly protective (adjusted OR $0 \cdot 07,95 \%$ CI $0 \cdot 008-0 \cdot 66, P=0 \cdot 02$ ), but wearing of gloves and gowns had no demonstrable effect. Wearing of N95 masks during each patient contact was also strongly protective, with an adjusted OR of $0 \cdot 1(95 \%$ CI $0 \cdot 02-0 \cdot 86, P=0 \cdot 04)$.

\section{DISCUSSION}

In this study, no adjustment was made for the effect of 'superspreaders' - who featured strongly in the Singapore outbreak - nor for any decrease in infectiousness over successive generations of cases: all exposures were treated as equivalent, regardless of timing within the outbreak or source of infection. An inherent limitation of this study was that viral load measurements were not available for any of the patients in TTSH. Data on times of first and last exposure were also incomplete: time of first and last exposure were missing for $78(83 \%)$ and $65(69 \%)$ out of 94 subjects. Variations in viral load may explain the wide range of infectiousness observed across patients and across outbreaks. Fluctuations in viral load and shedding during the clinical course may be associated with varying infectiousness during the clinical course of SARS. However, we encountered difficulty in our study with obtaining precise exposure history from subjects, some of whom had tended more than one patient, and all of whom had imperfect recall of an extremely stressful period. We felt this would have limited the value of any analysis of transmission risk by time of illness of the source patient or time of exposure of the contact patient. Although we analysed for differences in risk between long and short exposure durations and small and large distances from source, the failure to detect any effect is not surprising given the undoubted subjectivity and imprecision with which study subjects generally estimate time and distance.

It is unlikely that ORs of this magnitude could result primarily from recall bias relating to protective measures. Given the climate of anxiety and uncertainty that prevailed, it is likely that performance of risky procedures and omissions of PPE would have been equally salient to both cases and the controls. Moreover, the study was conducted almost contemporaneously with the outbreak, whereas confirmatory serology was only available later, thus minimizing the information bias to which retrospective studies are otherwise susceptible.

In this study, a history of contact with respiratory secretions from an infected patient was associated with a 22-fold increased odds of infection for the attending $\mathrm{HCW}$. Hand washing after attending patients was found to be strongly protective with a 15-fold amelioration of odds. The finding that wearing of gloves and gowns separately halved the odds of infection in univariate analysis yet failed to achieve statistical significance in multivariate analysis may be attributed to insufficient sample size. We also believe that, whereas this study accepted at face value subject responses on donning gloves and gowns, there exists broad variation in actual compliance to proper infection control technique, which we were unable to 
elucidate in this study. In the study by Seto et al. in Hong Kong [18], protection from gloves also failed to achieve statistical significance, but both gowns and hand washing were found to be protective. Much emphasis is presently given to droplet spread as the principal route of transmission for SARS, and to droplet precautions as the main protective measure. This study provides evidence for contact, both direct and indirect, with respiratory secretions or body fluids, as an additional major risk factor in the hospital setting. While the wearing of gloves and gowns should not be downplayed, this is a timely reminder of the importance of hand washing, as espoused by Semmelweis in the 19th century [21], albeit this time with the focus shifted to self-protection.

Consistent with the finding of the Hong Kong study, we found that wearing a mask was associated with a ten-fold lower odds of SARS. Although the local recommendation was for N95 use, this finding may simply attest to its effectiveness as a barrier to droplet spread rather than to the importance of airborne spread. Prolonged aerosol-generating procedures such as nebulization were not performed for any of the index cases, and there was no significant difference in the distribution of suctioning, intubation and oxygen administration between cases and controls. Within our study, given the 15 -fold protective effect observed for hand washing, an OR of $0 \cdot 1$ seems almost negligible. However, this estimate of effect is not very different from the Hong Kong study, where failure to wear a mask was associated with an increased OR for SARS of 13.

Given that the index cases in Singapore were ethnic Chinese who had travelled to Hong Kong, the slightly higher odds of SARS we observed for Chinese over non-Chinese HCWs is most plausibly attributed to the tendency of patients to seek to communicate in their mother tongue, rather than to any genetic predisposition.

In summary, these results provide confirmation that personal protective measures against droplet spread and contact with body fluids are effective against the nosocomial spread of SARS. Although SARS is viewed as being primarily spread by droplet transmission, this study additionally provides evidence that direct and indirect contact with respiratory and body fluids of patients is also an important, if underrated, risk factor. It provides a timely reminder of the importance of the long-advocated but oftneglected practice of hand washing between patient encounters.

\section{ACKNOWLEDGEMENTS}

The authors thank Nursing Officer Molly Wee, Staff Nurse Ai Kiau Soh and Mrs Phyllis Chew from the Department of Clinical Epidemiology, Tan Tock Seng Hospital, for their dedicated efforts in conducting the interviews.

\section{REFERENCES}

1. World Health Organization. Summary of probable SARS cases with onset of illness from 1 November 2002 to 31 July 2003. Geneva: World Health Organization, 26 September 2003 (http://www.who.int/csr/ sars/country/table2003_09_23/en/). Accessed January 2004.

2. Ksiazek TG, Erdman D, Goldsmith CS, et al. A novel coronavirus associated with severe acute respiratory syndrome. N Engl J Med 2003; 348: 1953-1966.

3. Drosten C, Gunther S, Preiser W, et al. Identification of a novel coronavirus in patients with severe acute respiratory syndrome. N Engl J Med 2003; 348: 19671976.

4. Peiris and colleagues. Novel coronavirus and severe acute respiratory syndrome. Lancet $2003 ; 361: 1312-$ 1314.

5. Chin JS (ed.). Control of communicable diseases in man, 17th edn. Washington, DC: American Public Health Association, 2000.

6. CDC. Guidelines for isolation precautions in hospitals. Atlanta, GA: Centers for Disease Control and Prevention, 1997 (http;//www.cdc.gov/ncidod/hip/ISOLAT/ Isolat.htm). Accessed January 2004.

7. WHO. Consensus document on the epidemiology of severe acute respiratory syndrome (SARS). Geneva: World Health Organization, 2003 (http://www.who. int/csr/sars/en/WHOconsensus.pdf). Accessed January 2003.

8. WHO environmental health team report on Amoy Gardens (http://www.info.gov.hk/info/ap/who-amoye. pdf). Accessed May 2004.

9. Park BJ, Peck AJ, Kuehnert J, et al. Lack of SARS transmission among healthcare workers, United States. Emerg Infect Dis 2004; 10: 244-248.

10. Giesecke J. Modern infectious disease epidemiology, 2nd edn. Stockholm: Arnold, 2002.

11. Anderson RM, May RM. Infectious diseases of humans: dynamics and control. Oxford: Oxford, 1991.

12. Hill AN, Longini IM. The critical vaccination fraction for heterogeneous epidemic models. Math Biosci 2003; 181: 85-106.

13. Bonabeau E, Toubiana L, Flahault A. The geographical spread of influenza. Proc R Soc Lond B 1998; 265: 2421-2425.

14. Ministry of Health, Singapore. Information for healthcare professionals. Singapore: Ministry of Health, 2003 (www.moh.gov.sg/sars/information/healthcare.html\# epidemiology). Accessed January 2004. 
15. Cable News Network. Canada: SARS knows no boundaries, April 2003 (http://edition.cnn.com/2003/ HEALTH/04/22/sars.canada/). Accessed January 2004.

16. WHO. Dr Carlo Urbani of the World Health Organization dies of SARS. Geneva: World Health Organization, 2003 (http://www.who.int/mediacentre/notes/ 2003/np6/en/). Accessed January 2004.

17. Ministry of Health, Singapore. MOH SARS press releases. Singapore: Ministry of Health, 2003 (http://app. moh.gov.sg/sars/news/update_details.asp?id $=1 \&$ mid =6580). Accessed January 2004 .

18. Seto WH, Tsang D, Yung RWH, et al. Effectiveness of precautions against droplets and contact in prevention of nosocomial transmission of severe acute respiratory syndrome (SARS). Lancet $2003 ; \mathbf{3 6 1}$ : 1519 1520.

19. CDC. NIOSH guide to the selection and use of particulate respirators certified under 42 CFR 84 . Atlanta, GA: Centers for Disease Control and Prevention, 1996 (http://www.cdc.gov/niosh/userguid.html). Accessed January 2004.

20. WHO. Case definitions for surveillance of severe acute respiratory syndrome (SARS). Geneva: World Health Organization, 2003 (http://www.who.int/csr/sars/casedefinition/en/). Accessed January 2004.

21. Daniels IR. Historical perspectives on health. Semmelweis: a lesson to relearn? J R Soc Health 1998; 118: 367-370. 